\title{
Effect of 1-MCP on Boll Development and Subtending Leaves of Cotton (Gossypium hirsutum L.) Plants
}

\author{
Yuan Chen ${ }^{*}$, J. Tom Cothren1, Dehua Chen ${ }^{2}$, Amir M. H. Ibrahim¹, Leonardo Lombardini ${ }^{3}$ \\ ${ }^{1}$ Department of Soil and Crop Sciences, Texas A \& M University, College Station, USA \\ ${ }^{2}$ Jiangsu Provincial Key Laboratory of Crops Genetics and Physiology, Yangzhou University, \\ Yangzhou, China \\ ${ }^{3}$ Department of Horticultural Sciences, Texas A \& M University, College Station, USA \\ Email: *henyua3@tamu.edu
}

Received 13 August 2014; revised 22 September 2014; accepted 23 October 2014

Copyright (C) 2014 by authors and Scientific Research Publishing Inc.

This work is licensed under the Creative Commons Attribution International License (CC BY).

http://creativecommons.org/licenses/by/4.0/

(c) (i) Open Access

\section{Abstract}

Ethylene regulates multiple physiological processes in cotton (Gossypium hirsutum L.) ranging from square and boll abscission to senescence. This field study investigated the effect of an ethylene inhibiting compound 1-methylcyclopropene (1-MCP) on boll development and the corresponding subtending leaves. The study was conducted in 2011 and 2012 at the Texas A \& M AgriLIFE Research Farm in Burleson County, TX. The study consisted of two rates of 1-MCP (0 and $10 \mathrm{~g}$ a.i. ha $^{-1}$ ) applied at one and two weeks after first flower. Boll development and subtending leaves were studied on the tagged flowers during the growing season. 1-MCP treatment increased cotton boll weight at 20 days after flowering. This study showed that 1-MCP-treated subtending leaves exhibited decreased membrane damage and lipid peroxidation, and higher chlorophyll content and photosynthetic efficiency at 20 to 30 days after flowering. The healthier state of subtending leaves should have provided more carbohydrates for the fruits which could partially explain the reason for the increased boll weight. However, this beneficial effect of 1-MCP did not last to the end of the growing season and failed to result in a yield increase ultimately. Multiple applications or extending effective duration of 1-MCP is desirable to enhance the activity of 1-MCP to make a significant difference in cotton yield.

\section{Keywords}

1-MCP, Ethylene, Abscission, Leaf Senescence, Subtending Leaf, Boll Development

${ }^{*}$ Corresponding author. 


\section{Introduction}

Stress-induced ethylene can be elicited by a number of factors including the following: high, freezing, and chilling temperature; water stress including drought and waterlogging; chemicals including herbicides and insects salivary fluids; physical wounding including bruising, cutting and insect biting; and pathogen [1] [2]. Ethylene is reported to stimulate fruit abortion in cotton plants [3]-[6]. Only $24 \%$ to $36 \%$ of flowers produced by cotton result in bolls for harvest [7]. Since boll retention is a major determinant of cotton yield [8]-[12], any means to enhance retention should increase the potential for yield. In addition, ethylene works as an elicitor of leaf and flower senescence [13]. Premature senescence caused a lower photosynthetic rate and less carbon accumulation and thereby decreased yield in cotton [14]. Thus, it is desirable to protect yield by antagonizing the ethylene effect that would subsequently lead to the reduction of fruit shedding and to a delay of senescence.

The plant growth regulator 1-methylcyclopropene (1-MCP) inhibits ethylene action and has been proven to be a useful product in postharvest studies to improve quality and shelf life of agricultural and horticultural products [15]. 1-MCP binds to the ethylene receptor site and has an affinity 10 times greater for the site than that of ethylene [15] [16]. Thus, 1-MCP may inhibit ethylene action by competing with ethylene for its receptor and thus alleviate or reduce adverse effects of stress.

In a cotton field study, under heat stress conditions, 1-MCP treatment at first flower (FF) and FF +2 weeks increased yield due to an increase of weight of bolls located in the lower half of the canopy compared to the untreated control. Also, in this study, reduced leaf antioxidant enzyme activity and an increased Photosystem II quantum efficiency was found in 1-MCP treated plants, indicating a potential of 1-MCP in reducing heat stress [17]. A positive effect of 1-MCP on cotton boll size and reduced stress level indicated by reduced glutathione reductase activity were reported for cotton field studies for three years [18]-[20]. 1-MCP treatment increased boll number on some nodes of the cotton plants under drought, but the increase was not enough to make a difference in cotton yield [21].

However, no cotton research has investigated how 1-MCP impacted the boll development process and thus resulted in the final yield. Studies by Kawakami et al. (2010) [17] only recorded the final boll weight response to 1-MCP. In addition, the leaf samples used in previous studies came from the main-stem, but the corresponding subtending leaves of bolls provide more than $60 \%$ of the total carbohydrates of developing reproductive organs [22]. The photosynthetic rate of leaves subtending bolls declines during active fruit growth, with the leaves subtending bolls reaching peak photosynthesis around the time of anthesis. Thus the photosynthetic capacity of the subtending leaf is out of phase with bolls for assimilate demand and more carbon must be transported to bolls from distant leaves [22] [23]. Because the availability of assimilates for boll development is important for fruit retention [24], factors which impact photosynthesis, such as stresses, can lead to fruit abortion [4]. Thus, it is important to study the impact of 1-MCP on subtending leaves to better understand the yield data. In the present study, boll distribution within the canopy was observed. Understanding how 1-MCP affects not only yield but also yield distribution that contributes to the final yield should provide insight into how the yield is impacted.

We hypothesized that 1-MCP has the potential to reduce the adverse effects caused by stress by delaying leaf senescence in subtending leaves, reducing fruit abscission, and potentially increasing boll size. The objectives of this study were to assess the effects of 1-MCP on the boll development process, subtending leaves of the corresponding bolls, and boll distribution.

\section{Materials and Methods}

The study was conducted at the Texas A \& M Agri LIFE Research Farm in Burleson County on a Westwood silt loam field (fine-silty mixed thermic Fluventic Ustochrept). Cotton (cv. FM832LL) was seeded on April 10th in 2011 and 2012 at a density of 11 seeds $\mathrm{m}^{-2}$. Each plot consisted of four rows that were $9.73 \mathrm{~m}$ in length and 1.02 $\mathrm{m}$ wide. Each plot had four 1.02-m-wide rows that were $9.73 \mathrm{~m}$ in length. Furrow irrigation was used when necessary to water plants during the growing season. Fertility, disease prevention, insect and weed control were performed according to the Texas A \& M Agri LIFE Extension Service local recommendations. Harvest aids (1.106 kg a.i. $\mathrm{ha}^{-1}$ ethephon plus $0.056 \mathrm{~kg}$ a.i. $\mathrm{ha}^{-1}$ thidiazuron and $0.421 \mathrm{~kg}$ a.i. ha ${ }^{-1}$ tribufos) were applied at approximately 60\% open bolls. Weather data for the year 2011 and 2012 growing seasons were showed in Figure 1.

A randomized complete block design with three replications was utilized for the two treatments: untreated 


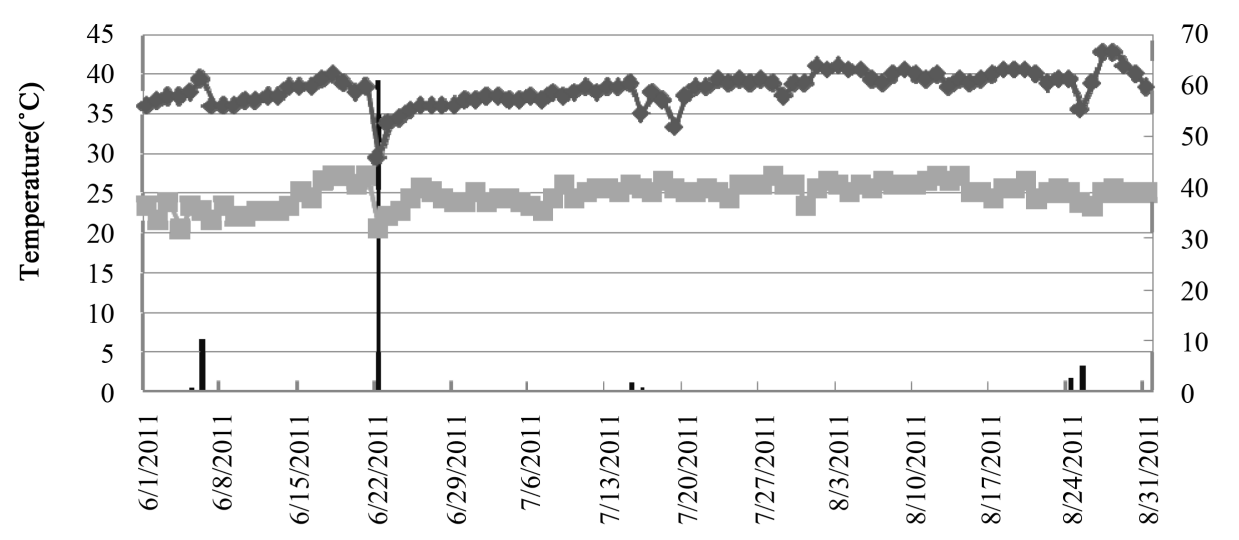

60

50

rainfall (inch)

High T

Low T

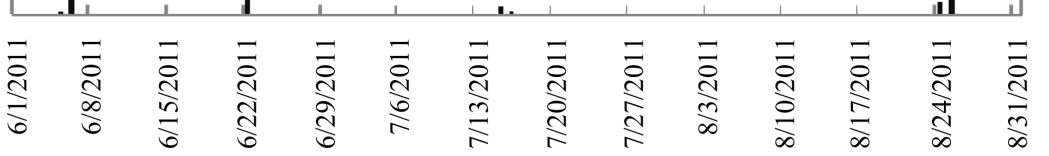

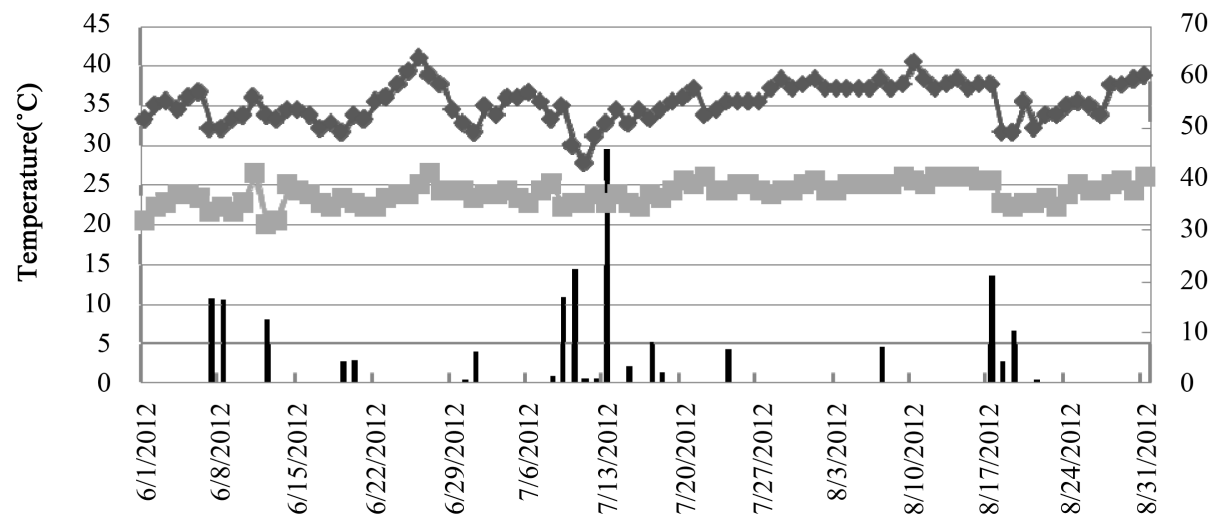

(b)

rainfall (inch)

High T

Low T

Figure 1. Weather data for 2011 (a) and 2012 (b).

control and 1-MCP treatment. The center two rows of each four-row plot were treated for evaluation. At first flower plus one week $(\mathrm{FF}+1)$ and first flower plus two weeks $(\mathrm{FF}+2), 1-\mathrm{MCP}\left(10 \mathrm{~g} \mathrm{a.i.} \mathrm{ha}{ }^{-1}\right.$ at $103 \mathrm{~L} \cdot \mathrm{ha}^{-1}$ with 0.0375\% Silwet L77) of the AF625 formulation (Rohm \& Hass, Philadelphia, PA) was sprayed to cotton leaves using a compressed air sprayer with 8002XR nozzles according to treatments. One hundred white flowers from the first sympodial fruiting position from the main stem nodes 10 to 15 were tagged on the FF +1 week per each plot. Bolls and the corresponding subtending leaves were collected at 20, 30, 40, and 50 days after flower and subjected to measurement. Five bolls per each plot were sampled at each time period for boll weight measurement. Three subtending leaves per each plot were measured for lipid peroxidation, membrane leakage, chlorophyll fluorescence, and chlorophyll content measurement.

\subsection{Lipid Peroxidation}

This method was obtained from Dr. Dehua Chen (Personal Communication, 2010).

Malondialdehyde (MDA, the final product of lipid peroxidation) was measured to test the level of lipid peroxidation. A $0.8 \mathrm{~g}$ leaf sample from the sixth uppermost fully-extended leaves was homogenized in $10 \mathrm{~mL}$ of $10 \%$ trichloroacetic acid (TCA) and centrifuged for $10 \mathrm{~min}$ at $4000 \mathrm{~g}$. A 3-mL portion of supernatant was mixed with $3 \mathrm{~mL}$ of $10 \%$ TCA containing $0.6 \%$ 2,4,6-tribromoanisole (TBA). The mixture was incubated in a $100^{\circ} \mathrm{C}$ water bath for $15 \mathrm{~min}$. Samples were centrifuged for $10 \mathrm{~min}$ at $4000 \mathrm{~g}$ after 5 -min in an ice bath. The absorbance for the supernatant was determined spectrophotometrically (DU Series 500, Beckman Instruments Inc., CA) at $532 \mathrm{~nm}, 600 \mathrm{~nm}$, and $450 \mathrm{~nm}$ to calculate the MDA content. Lipid peroxidation was expressed as the MDA concentration in $\mu \mathrm{M} \cdot \mathrm{g}^{-1} \mathrm{FW}$.

\subsection{Membrane Leakage}

Membrane leakage was measured to show the level of plasma membrane integrity using the method of Djana- 
guiraman et al. (2011) [25] with some modification. Five 1-cm-diameter leaf discs from the fifth fully extended uppermost leaf were sampled and incubated in $10-\mathrm{mL}$ of double distilled water $\left(\mathrm{ddH}_{2} \mathrm{O}\right)$ in glass tubes at room temperature. After $48 \mathrm{~h}$ of incubation, initial electrical conductivity (IEC) was taken using a calibrated conductivity meter (Oaklon CON11, EUTECH instrument, IL). Leaf discs were then autoclaved at $120^{\circ} \mathrm{C}$ for 15 min. After the solution cooled to room temperature final electrical conductivity (FEC) was measured, and the membrane damage was calculated from the equation: Membrane damage $=($ IEC/FEC $) \times 100$.

\subsection{Chlorophyll Fluorescence}

Chlorophyll fluorescence was obtained in light adapted leaves at the fourth position from the uppermost fullyexpanded leaves with a fluorometer (PAM-2100, Walz, Germany). The value of Yield (ФPS photosystem II effective quantum efficiency, was the ratio of number of photons absorbed to number of photons emitted by fluorescence. Stressed plants usually exhibit lower $\Phi P S_{\text {II }}$ values because the number of photons absorbed tends to be lower under stressed conditions.

\subsection{Chlorophyll Content}

Chlorophyll content was measured by the ethanol extraction method according to Djanaguiraman et al. (2011) [25]. Six 1-cm-diameter leaf discs from the fifth uppermost fully-extended leaves were incubated in $10 \mathrm{~mL}$ of $100 \%$ ethanol for $24 \mathrm{~h}$ in the dark. Absorbance of the extract was recorded at $645 \mathrm{~nm}$ and $663 \mathrm{~nm}$ with a spectrophotometer (DU Series 500, Beckman Instruments Inc., CA).

\subsection{Box Mapping and Harvest Data}

Immediately before machine harvest, 5 randomly chosen plants from the two center rows per designated plot were sampled to conduct box mapping according to da Costa et al. (2011) [26]. Box mapping was used to determine number of vegetative, reproductive, and main-stem nodes, boll weight, plant height, and boll number by individual position and node to determine yield distribution within the canopy. Internode length was measured as the fraction of plant height to main-stem node number. Abscised fruit was measured by recording scars left on the sympodial branches. Fruit retention at 1st, 2nd and 3rd positions on sympodial branches and on different reproductive nodes were determined. Two weeks after harvest aid application, two center rows were harvested with a two-row spindle picker.

\subsection{Data Analysis}

The statistical significance between means were analyzed by analysis of variance (ANOVA) and multiple mean comparisons were determined by LSD $(\alpha=0.05)$ in SAS 9.3 (SAS Institute, NC). Homogeneity of variance across years was tested for each variable. Data presented hereafter are pooled for each experiment, from the repeated series.

\section{Results}

The results were averaged across the years because no year and treatment interactions were detected. Lint yield was not impacted by 1-MCP. Lint yield from the 1-MCP treatment was almost identical to that of the untreated control: the lint yield of untreated control treatment was $1146 \mathrm{~kg}$ per hectare and the lint yield of 1-MCP treatment was $1133 \mathrm{~kg} /$ hectare (Figure 2).

To further understand the effect of 1-MCP on yield components and yield distribution, box mapping before harvest was measured. According to box mapping data, no significant differences were caused by 1-MCP on boll retention rate for either year of our study. But a numerical decrease of boll retention rate in 1-MCP treated plants was detected both years, since 1-MCP decreased boll retention rate by $3 \%$ and $6 \%$ compared to the untreated control in the year 2011 and 2012, respectively (Table 1). 1-MCP treatment increased boll weight numerically in both years of our study according to box mapping data (Table 1). These boll weight results were consistent with the boll weight study in which boll weight was recorded from flowers at 20, 30, 40 and 50 DAF to study the development process. 1-MCP treated plants showed a higher boll dry weight compared to untreated ones at 20 DAF. However, there was no significant 1-MCP effect on boll weight at 30, 40, and 50 DAF. The 


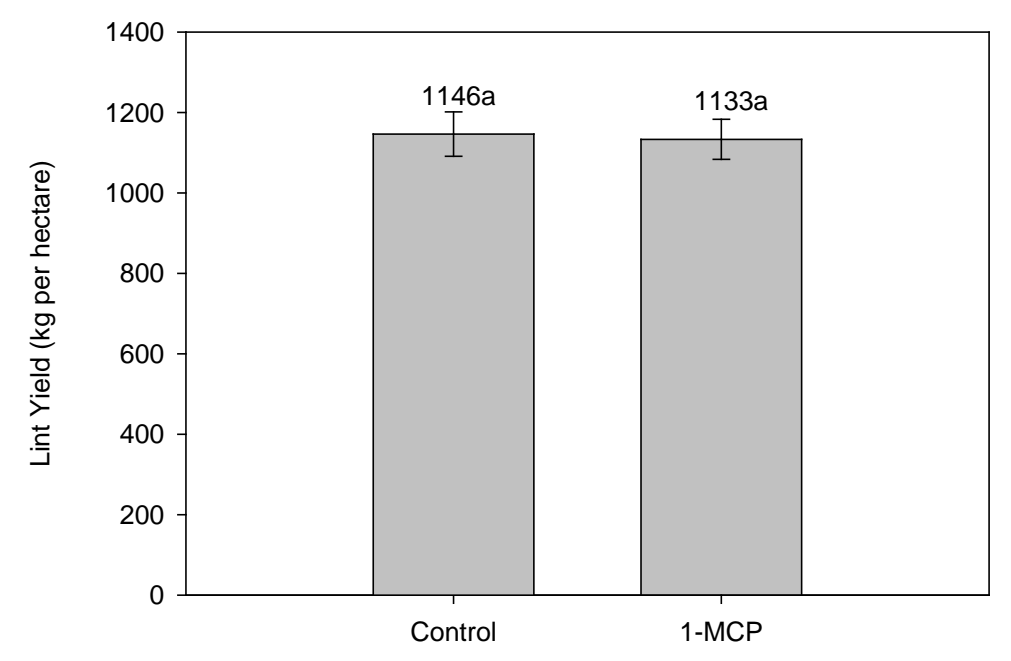

Figure 2. The effect of 1-MCP on cotton lint yield over two years (2011 and 2012). Same letters above histograms represent non-significant differences $(P=$ 0.05). Vertical bars indicate SE.

Table 1. The effect of 1-MCP on retention rate, boll number per plant, and boll weight per boll in 2011 and 2012.

\begin{tabular}{|c|c|c|c|c|c|c|}
\hline \multirow{2}{*}{ 1-MCP } & \multicolumn{2}{|c|}{ Retention } & \multicolumn{2}{|c|}{ Boll Number } & \multicolumn{2}{|c|}{ Boll Weight } \\
\hline & 2011 & 2012 & 2011 & 2012 & 2011 & 2012 \\
\hline g a.i. ha ${ }^{-1}$ & \multicolumn{2}{|c|}{$\%$} & \multicolumn{2}{|c|}{ no. plant ${ }^{-1}$} & \multicolumn{2}{|c|}{ g.boll ${ }^{-1}$} \\
\hline 0 & 36.79 & 40.93 & 13.60 & 12.75 & 4.78 & 5.10 \\
\hline 10 & 35.68 & 38.62 & 13.44 & 12.75 & 4.94 & 5.15 \\
\hline $\operatorname{LSD}(0.05)$ & 7.46 & 5.6 & 4.06 & 2.02 & 0.32 & 0.32 \\
\hline
\end{tabular}

numerical but not significant increase of boll weight at 50 DAF was consistant with the box mapping data that the final boll weight was not significantly impacted by 1-MCP application (Figure 3).

In order to test whether 1-MCP could delay senescence in cotton plants, the physiological and biochemical traits of premature leaf senescence were determined in the subtending leaves. Application of 1-MCP decreased membrane leakage at 30 days after flower (DAF) in the subtending leaves, indicating a better cell membrane integrity. However, this beneficial effect of 1-MCP treatment was minimized in the growing season, no significant 1-MCP effect on membrane integrity was detected on 40 or 50 DAF (Figure 4(a)). Similar trends were observed for the measurement of MDA content, chlorophyll fluorescence, and chlorophyll content of the subtending leaves. 1-MCP treatment resulted in a lowered MDA content at 20 and 30 DAF (Figure 4(b)), an increased chlorophyll fluorescence at 20 DAF (Figure 4(c)), and an improved chlorophyll content at 30 DAF (Figure 4(d)), which reflects better cell membrane integrity, less oxidative damage, higher photosynthetic efficiency and less pigment loss. Again 1-MCP application failed to cause a significant effect on 40 or 50 DAF on those traits although it works at the early flower stage.

\section{Discussion}

1-MCP treatment made no difference in lint yield compared to the untreated control in our present study. This result agrees with our ethephon and 1-MCP study data which showed that 1-MCP treatment had lint yield similar to the untreated control (unpublished data). Diverging reports exist on the effect of 1-MCP on cotton yield. 1-MCP treated cotton did not show a significant increase in cotton yield in comparison with the untreated control in Arkansas in either 2006, 2007, or 2008 [18]-[20]. But the combined data of 2006 and 2007 in Arkansas showed that 1-MCP increased the yield of field-grown cotton under high temperature stress, and this increase of yield was due to higher boll weight [17]. The positive effect of 1-MCP on cotton yield was only observed in 2005 but not in 2006 in Texas [27]. No beneficial effect of 1-MCP treatment on cotton yield was found in 2007 


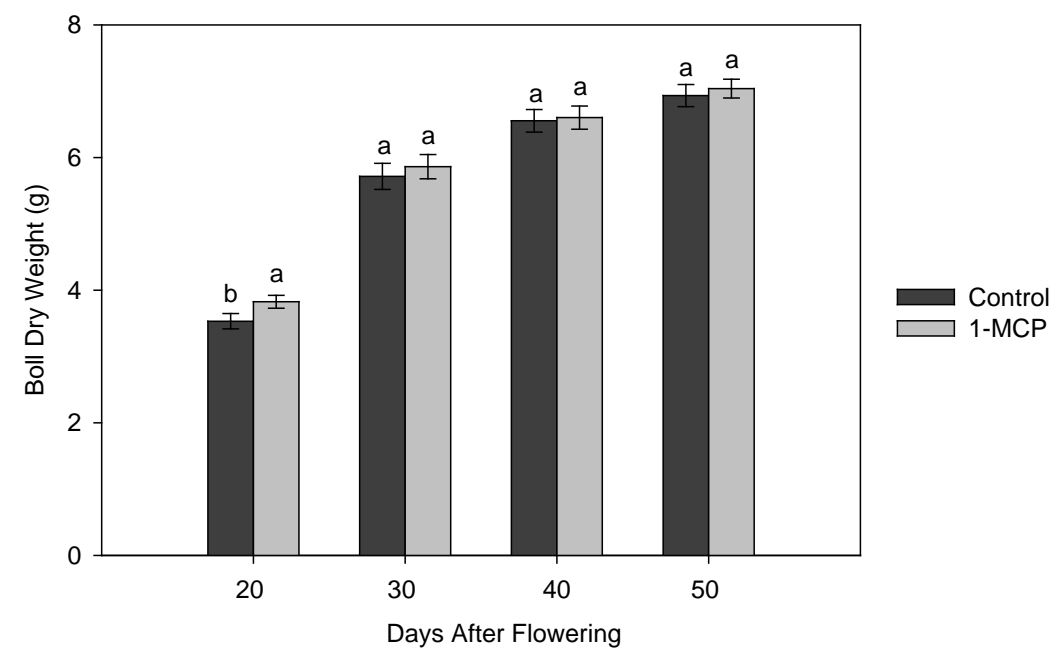

Figure 3. The effect of 1-MCP on boll weight over two years (2011 and 2012). Same letters above histograms within each time interval represent non-significant differences $(P=0.05)$. Vertical bars indicate SE.
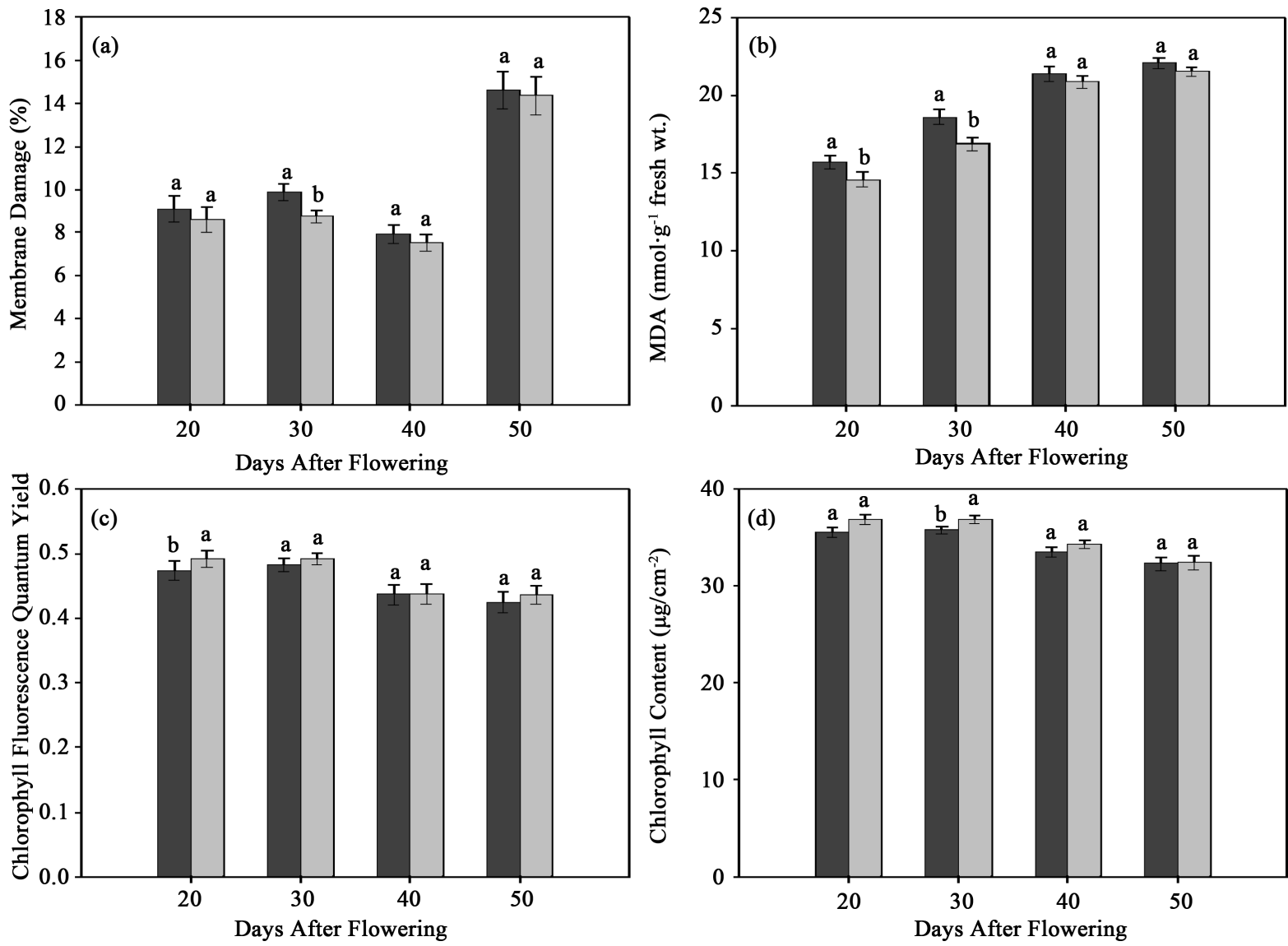

Figure 4. The effect of untreated control (dark grey) and 1-MCP (light grey) on membrane damage (a), MDA content (b), leaf chlorophyll fluorescence (c), and leaf chlorophyll content (d) over two years (2011 and 2012). Same letters above histograms within each time interval represent non-significant differences $(P=0.05)$. Vertical bars indicate SE.

and 2008 in Texas [26]. Application of 1-MCP increased cotton height, boll number on some nodes, and uppermost first position harvestable boll under water stressed conditions in Arizona. However, the potential was not realized in increased cotton yield [21]. Thus, research conducted in Arizona and most research conducted in 
Texas failed to detect the yield difference caused by 1-MCP. The difference was only observed in the combined data of two years in Arkansas but not in individual years. The different effects of 1-MCP on cotton yield in different locations and different years were probably due to different weather conditions. Long durations of high temperature often occurs during the boll development stage in Texas, which suggests that 1-MCP can work under a moderate stress levels, but not under high stress levels.

In the present study, numerical differences were detected in both years with 1-MCP treated plants exhibiting lower retention rate. da Costa et al. (2011) [26] found that 1-MCP application resulted in 22\% higher fruit shed at 22 days after treatment. They also mentioned that 1-MCP temporarily increased ethylene emissions compared to the untreated control at 1 day after treatment (unpublished data 2008 and 2009). Research in pears (Pyrus communis L. cv. Conference) also reported a burst of ethylene following 1-MCP treatment [28]. Ethylene promotes the abscission layer formation in the peduncle in cotton plants and thus leads to fruit abortion, and ethylene production plays a primary role in early season square and boll abortion [3]-[6]. Thus, this increase of abscission by 1-MCP treatment was probably due to the burst of ethylene noted at the very beginning following treatment with 1-MCP. In contrast, many studies showed a potential for 1-MCP to increase fruit retention in cotton, soybean (Glycine max L. Merr.), and wheat (Triticum aestivum L.). The results of the soybean study showed that 1-MCP treatment increased pod set percentage and decreased flower abscission, and that these beneficial effects of 1-MCP were greater under high temperature in contrast to optimum temperature [25]. 1-MCP application decreased heat stress induced kernel abortion in wheat [29]. 1-MCP increased boll retention in one of two years in Texas [27]. Kawakami et al. (2010) [17] reported that 1-MCP had no significant effect on boll abscission in field grown cotton. The diverging effect of 1-MCP on fruit retention could be contributed to different plants, different 1-MCP formulations and varying growth conditions.

According to box mapping data, 1-MCP treatment increased boll weight numerically in both years of our study. In consistant to this results, 1-MCP treated plants showed a higher boll dry weight compared to untreated ones at 20 DAF, but not at 30, 40, and 50 DAF. Application of 1-MCP decreased membrane leakage at 30 days after flower (DAF), lowered MDA content at 20 and 30 DAF, increased chlorophyll fluorescence at 20 DAF, and improved chlorophyll content at 30 DAF in the subtending leaves. Thus, at 20 and 30 DAF, the beneficial effects of 1-MCP on antioxidant potential and photosynthetic efficacy were observed. The cotton bolls primarily get carbohydrates produced by the subtending leaves. Thus, combined with a consistent period of beneficial effects of 1-MCP treatment on boll weight and subtending leaves, the increased boll weight may be partially contributed by the greater photosynthetic efficacy and extended photosynthetically active period in subtending leaves under 1-MCP treatment. These results suggest 1-MCP-treated plants exhibited delayed leaf senescence, which resulted in an extended active photosynthetic period and increased production of carbon assimilates for developing bolls, and thus increased potential for cotton productivity. Another possible explanation for higher boll weight was the compensation due to fruit abortion. Cotton plants may compensate for the loss of squares by providing more carbon allocation toward boll set and increasing boll weight [30], and taller plants [7]. Therefore, the increased boll weight may be related to the compensation caused by fruit loss.

However, the 1-MCP treatment did not make a significant difference in boll weight at final harvest. This may be due to the long growing season of cotton compared to the relatively short duration effect of 1-MCP. 1-MCP decreased ethylene production for up to 4 days after treatment in soybean [25]. In comparison to the short duration of 1-MCP effect on ethylene levels, 1-MCP treatment increased antioxidant enzyme activity of catalase (CAT) and superoxide dismutase (SOD) up to 15 days after treatment, and photosynthetic rate up to 11 days after treatment [25]. In a study to test the effect of 1-MCP on water-stressed cotton plants, the water withholding process was conducted with a five-day cycle for three times. By the end of the experiment (14 days after 1-MCP treatment), more active antioxidant enzymes and less membrane leakage were detected in 1-MCP-treated stressed plants [31]. The effect of 1-MCP treatment on fluorescence yield and glutathione reductase levels can last up to three weeks after treatment in a cotton field study under heat stress [17]. In our present study, 1-MCP effect on leaf senescence and activity last for up to 2 weeks. Thus, the beneficial effects of 1-MCP were minimized by the environmental stress that happened later in the growing season. Therefore, the numerical increase of boll weight combined with the numerical decrease in boll retention in 1-MCP treated plants resulted in similar final lint yields.

\section{Conclusion}

1-MCP treatment increased cotton boll weight at 20 days after flowering. This increase was likely associated 
with healthier subtending leaves as reflected by decreased membrane damage at 30 and $40 \mathrm{DAF}$, and lower lipid peroxidation at 20 and $30 \mathrm{DAF}$, higher chlorophyll content at $30 \mathrm{DAF}$, and greater photosynthetic efficiency at $20 \mathrm{DAF}$. The healthier state of subtending leaves indicated a longer photosynthetic productive period and thus a potential for more assimilates being produced for bolls. However, the beneficial effect of 1-MCP was not enough to affect final lint yield and the potential of yield increase was not realized due to the relatively short duration effect of 1-MCP compared to the long growing season. Multiple applications or modification of the formulation to extend effective duration of the compound is desirable to enhance the activity of 1-MCP to make a significant difference in cotton yield.

\section{Acknowledgements}

We are grateful for the financial support from Agro Fresh. We also would like to thank Clayton Lewis and the entire Cotton Physiology Workgroup for their assistance for the field study. I also appreciate the technical assistant provided by Dr. Yujin Wen.

\section{References}

[1] Lieberman, M. (1979) Biosynthesis and Action of Ethylene. Annual Review of Plant Physiology and Plant Molecular Biology, 30, 533-591. http://dx.doi.org/10.1146/annurev.pp.30.060179.002533

[2] Morgan, P.W. and Drew, M.C. (1997) Ethylene and Plant Responses to Stress. Physiologia Plantarum, 100, 620-630. http://dx.doi.org/10.1034/j.1399-3054.1997.1000325.x

[3] Guinn, G. (1976) Water Deficit and Ethylene Evolution by Young Cotton Bolls. Plant Physiology, 57, 403-405. http://dx.doi.org/10.1104/pp.57.3.403

[4] Guinn, G. (1982) Causes of Square and Boll Shedding in Cotton. USDA Technical Bulletins, US Government Printing Office, Washington DC, 1-22.

[5] Guinn, G. (1982) Fruit Age and Changes in Abscisic-Acid Content, Ethylene Production, and Abscission Rate of Cotton Fruits. Plant Physiology, 69, 349-352. http://dx.doi.org/10.1104/pp.69.2.349

[6] Lipe, J.A. and Morgan, P.W. (1973) Ethylene, a Regulator of Young Fruit Abscission. Plant Physiology, 51, 949-953. http://dx.doi.org/10.1104/pp.51.5.949

[7] Kennedy, C.W., Smith, W.C. and Jones, J.E. (1991) Chemical Efficacy of Early Square Removal and Subsequent Productivity of Superokra-Leaf Cotton. Crop Science, 31, 791-796. http://dx.doi.org/10.2135/cropsci1991.0011183X003100030050x

[8] Boquet, D.J., Hutchinson, R.L. and Breitenbeck, G.A. (2004) Long-Term Tillage, Cover Crop, and Nitrogen Rate Effects on Cotton: Yield and Fiber Properties. Agronomy Journal, 96, 1436-1442. http://dx.doi.org/10.2134/agronj2004.1436

[9] Hake, K., et al. (1992) Sqaure Retention. In: Cotton Phsiology Today Newletter, National Cotton Council, Memphis, Technical Service.

[10] Wells, R. and Meredith, W.R. (1984) Comparative Growth of Obsolete and Modern Cotton Cultivars. 3. Relationship of Yield to Observed Growth-Characteristics. Crop Science, 24, 868-872. http://dx.doi.org/10.2135/cropsci1984.0011183X002400050010x

[11] Worley, S., Culp, T.W. and Harrell, D.C. (1974) The Relative Contributions of Yield Components to Lint Yield of Upland Cotton, Gossypium hirsutum L. Euphytica, 23, 399-403. http://dx.doi.org/10.1007/BF00035885

[12] Wu, J.X., Jenkins, J.N., McCarty, J.C. and Watson, C.E. (2005) Comparisons of Two Statistical Models for Evaluating Boll Retention in Cotton. Agronomy Journal, 97, 1291-1294. http://dx.doi.org/10.2134/agronj2004.0216

[13] Jiang, W., Sheng, Q., Zhou, X.J., Zhang, M.J. and Liu, X.J. (2002) Regulation of Detached Coriander Leaf Senescence by 1-Methylcyclopropene and Ethylene. Postharvest Biology and Technology, 26, 339-345. http://dx.doi.org/10.1016/S0925-5214(02)00068-6

[14] Wright, P.R. (1999) Premature Senescence of Cotton (Gossypium hirsutum L.) —Predominantly a Potassium Disorder Caused by an Imbalance of Source and Sink. Plant and Soil, 211, 231-239. http://dx.doi.org/10.1023/A:1004652728420

[15] Blankenship, S.M. and Dole, J.M. (2003) 1-Methylcyclopropene: A Review. Postharvest Biology and Technology, 28, 1-25. http://dx.doi.org/10.1016/S0925-5214(02)00246-6

[16] Sisler, E.C., Dupille, E. and Serek, M. (1996) Effect of 1-Methylcyclopropene and Methylenecyclopropane on Ethylene Binding and Ethylene Action on Cut Carnations. Plant Growth Regulation, 18, 79-86. http://dx.doi.org/10.1007/BF00028491 
[17] Kawakami, E.M., Oosterhuis, D.M. and Snider, J.L. (2010) 1-Methylcyclopropene Effects on the Physiology and Yield of Field-Grown Cotton. Journal of Cotton Science, 14, 233-239.

[18] Kawakami, E.M., Oosterhuis, D.M., Gonias, E.D. and Bibi, A.C. (2006) Effect of 1-MCP on the Growth and Yield of Cotton. Summaries of Arkansas Cotton Research 2006, 58-61.

[19] Kawakami, E.M., Oosterhuis, D.M. and Snider, J.L. (2007) Effect of 1-MCP on the Physiology and Yield of Cotton. Summaries of Arkansas Cotton Research 2007, 90-95.

[20] Storch, D.K., Oosterhuis, D.M. and Kawakami, E.M. (2008) Effect of 1-Methylcyclopropene on the Biochemistry and Yield of Field-Grown Cotton. Summaries of Arkansas Cotton Research 2008, 63-67.

[21] Wang, G. and Asiimwe, R.K. (2010) Effects of 1-MCP and Quadris on Cotton Growth and Yield. Arizona Cotton Report, 28-33.

[22] Wullschleger, S.D. and Oosterhuis, D.M. (1990) Photosynthetic Carbon Production and Use by Developing Cotton Leaves and Bolls. Crop Science, 30, 1259-1264. http://dx.doi.org/10.2135/cropsci1990.0011183X003000060021x

[23] Constable, G.A. and Rawson, H.M. (1980) Carbon Production and Utilization in Cotton: Inferences from a Carbon Budget. Australian Journal of Plant Physiology, 7, 539-553. http://dx.doi.org/10.1071/PP9800539

[24] Hearn, A.B. (1972) The Growth and Performance of Rain-Grown Cotton in a Tropical Upland Environment: II. The Relationship between Yield and Growth. The Journal of Agricultural Science, 79, 137-145. http://dx.doi.org/10.1017/S0021859600025466

[25] Djanaguiraman, M., Prasad, P.V.V. and Al-Khatib, K. (2011) Ethylene Perception Inhibitor 1-MCP Decreases Oxidative Damage of Leaves through Enhanced Antioxidant Defense Mechanisms in Soybean Plants Grown under High Temperature Stress. Environmental and Experimental Botany, 71, 215-223. http://dx.doi.org/10.1016/j.envexpbot.2010.12.006

[26] da Costa, V.A., Cothren, J.T. and Bynum, J.B. (2011) Abiotic Stress Effects on Plant Growth and Yield Components of 1-MCP Treated Cotton Plants. Agronomy Journal, 103, 1591-1596. http://dx.doi.org/10.2134/agronj2010.0481

[27] Scheiner, J.J. (2007) Effect of 1-Methylcyclopropene on Upland Cotton. Texas A \& M University, College Station.

[28] de Wild, H.P.J., Otma, E.C. and Peppelenbos, H.W. (2003) Carbon Dioxide Action on Ethylene Biosynthesis of Preclimacteric and Climacteric Pear Fruit. Journal of Experimental Botany, 54, 1537-1544. http://dx.doi.org/10.1093/jxb/erg159

[29] Hays, D.B., Do, J.H., Mason, R.E., Morgan, G. and Finlayson, S.A. (2007) Heat Stress Induced Ethylene Production in Developing Wheat Grains Induces Kernel Abortion and Increased Maturation in a Susceptible Cultivar. Plant Science, 172, 1113-1123. http://dx.doi.org/10.1016/j.plantsci.2007.03.004

[30] Stewart, S.D., Layton, M.B., Williams, M.R., Ingram, D. and Maily, W. (2001) Response of Cotton to Prebloom Square Loss. Journal of Economic Entomology, 94, 388-396. http://dx.doi.org/10.1603/0022-0493-94.2.388

[31] Kawakami, E.M., Oosterhuis, D. and Snider, J. (2010) Physiological Effects of 1-Methylcyclopropene on Well-Watered and Water-Stressed Cotton Plants. Journal of Plant Growth Regulation, 29, 280-288. http://dx.doi.org/10.1007/s00344-009-9134-3 
Scientific Research Publishing (SCIRP) is one of the largest Open Access journal publishers. It is currently publishing more than 200 open access, online, peer-reviewed journals covering a wide range of academic disciplines. SCIRP serves the worldwide academic communities and contributes to the progress and application of science with its publication.

Other selected journals from SCIRP are listed as below. Submit your manuscript to us via either submit@scirp.org or Online Submission Portal.
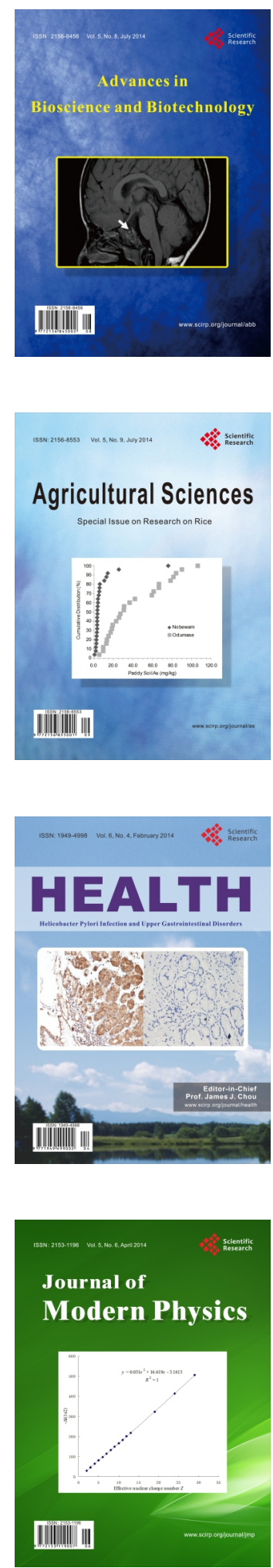
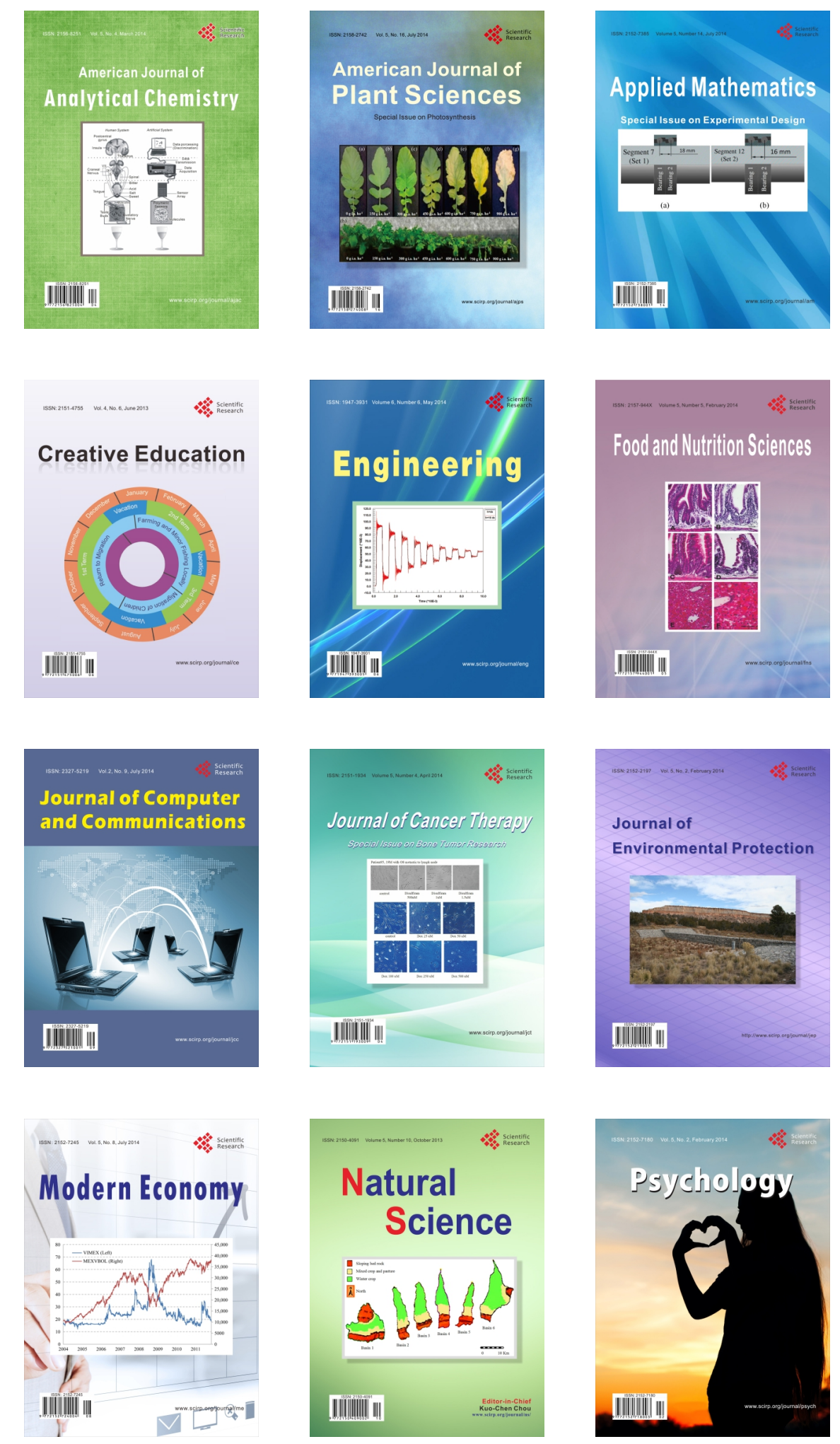